\title{
Eating patterns and nutritional characteristics associated with sleep duration
}

\author{
Sangmi Kim, Lisa A DeRoo and Dale P Sandler* \\ Epidemiology Branch, National Institute of Environmental Health Sciences, National Institutes of Health, \\ PO Box 12233 - MD A3-05, 111 T.W. Alexander Drive, Research Triangle Park, NC 27599, USA
}

Submitted 2 June 2009: Accepted 11 August 2009: First published online 29 October 2010

\begin{abstract}
Objective: To identify major meal and snack eating patterns, and examine their relationships with sleep duration.

Design: The analyses included 27983 participants in a prospective cohort study of women aged 35 to 74 years in the USA or Puerto Rico.

Results: The principal component analysis of eight meal and snack frequency items at different times across the day yielded two major eating patterns: (i) eating during conventional eating hours (defined as times from breakfast to dinner); and (ii) dominance of snacks over meals. Comparing the identified eating patterns among women with varying sleep duration $(<5,5-5 \cdot 9,6-6 \cdot 9,7-7 \cdot 9,8-8 \cdot 9,9-9 \cdot 9$ and $\geq 10 \mathrm{~h}$ daily), the tendency for eating during conventional eating hours decreased with decreasing sleep duration: adjusted mean score of $-0.54(95 \% \mathrm{CI}-0 \cdot 68,-0 \cdot 41)$ in women sleeping for $<5$ h daily $v \cdot 0 \cdot 08$ (95\% CI 0.06, 0.11) among those with $7-7 \cdot 9 \mathrm{~h}$ of sleep daily. The extent of snack dominance over meals increased in women with shorter sleep. Women with long $(\geq 10 \mathrm{~h}$ ) sleep duration had eating patterns similar to those with short $(<6 \mathrm{~h})$ sleep duration. Lower tendency for eating during conventional eating hours and greater snack dominance over meals were also related to higher intakes of fat and sweets for energy and lower intakes of fruits and vegetables. Conclusions: Disrupted eating patterns and diet of poor nutritional quality may exacerbate the development of obesity and metabolic diseases in habitual short and very long sleepers.
\end{abstract}

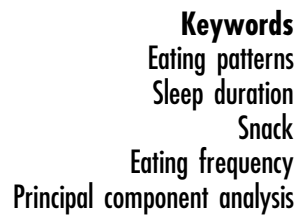

Keywords

Eating patterns

Snack

Principal component analysis
Increasing attention has been given to the potential metabolic implications of inadequate sleep. Short sleep and, to a lesser extent, long sleep duration may increase the risk of developing obesity ${ }^{(1-4)}$ and metabolic diseases ${ }^{(5,6)}$, possibly via alterations in metabolic regulation and appetite ${ }^{(7,8)}$.

Inadequate sleep duration may also modify eating patterns, thereby mediating or contributing to the observed relationship between sleep duration and obesity. Sleep duration in theory influences the time available for eating and the time of the day that eating occurs. Like most physiological actions and behaviours, eating practices are regulated in response to the sleep-wake cycle, which is the master output rhythm of the circadian $\operatorname{clock}^{(9)}$. Moreover, several characteristics of eating practices such as skipping breakfast, late eating time and low meal frequency have been related to altered metabolic response, poor nutritional quality and obesity ${ }^{(10-15)}$. In a previous study, a higher prevalence of skipping breakfast was observed in persons with short sleep than in persons with normative sleep hours ${ }^{(16)}$. However, we are unaware of studies characterizing eating patterns in relation to sleep duration.
A major objective of the present study was to examine the relationship between sleep duration and eating patterns. It has been well documented that individual eating episodes are highly interrelated; i.e. the timing and satiety of the previous eating episode largely determine the time and size of the following eating episode ${ }^{(12)}$. Therefore, we first used principal component analysis to identify major eating patterns among 27983 women in the Sister Study and then evaluated their relationships with sleep duration. We also chose obesity and older age (age $\geq 55$ years) a priori as potential effect modifiers based on previous literature suggesting altered meal and snack eating patterns in obese ${ }^{(10,13)}$ and older individuals ${ }^{(17,18)}$.

\section{Materials and methods}

\section{Sister Study}

The National Institute of Environmental Health Sciences (NIEHS) Sister Study (www.SisterStudy.org) is a prospective cohort study of environmental and genetic 
risk factors for breast cancer and other endpoints in approximately 50000 women aged 35-74 years who do not have breast cancer themselves but have a sister who was diagnosed with the disease. Participants are volunteers recruited through professional and volunteer organizations, breast cancer advocacy groups, health professionals, the media, outreach to specific populations, the Internet and word of mouth. Eligibility criteria include residence in the USA or Puerto Rico, age 35 to 74 years, ability to complete the study in English or Spanish, and having a full or halfsister who has had breast cancer. Recruitment began in four US cities in August 2003, opened nationally in October 2004 and ended in April 2009. Women who joined the study and provided written informed consent completed self-administered questionnaires (diet, family history, use of personal care products) and a two-part computer-assisted telephone interview to collect information on known and suspected breast cancer risk factors. Participating women also had a home visit for blood collection during which questionnaires and other biological and environmental samples were retrieved and height, weight, hip circumference, waist circumference and blood pressure were measured. The study was approved by the Institutional Review Boards of NIEHS, the National Institutes of Health (NIH) and the Copernicus Group.

Out of 29316 women who completed the interview by June 2007, 28735 provided information on both daily sleep duration (no. missing $=29$ ) and eight meal and snack frequency questions (no. missing $=552$ ). We further excluded thirty-two women who reported implausible values on sleep duration (predefined as $<3$ or $>12$ h of sleep daily), 471 women with implausible daily energy intake (defined as $<2092 \mathrm{~kJ} / \mathrm{d}(<500 \mathrm{kcal} / \mathrm{d})$ or $>14644 \mathrm{~kJ} / \mathrm{d}$ (>3500 kcal/ d) derived from an FFQ) and 249 women with poor selfreported health status who might have had unusual sleep and eating behaviours, leaving 27983 in the final analysis.

\section{Main study variables}

Sleep duration

Women were asked about average daily sleep duration using the following question: 'About how many hours and/or minutes of sleep per (night/day) do you get on average?' Study subjects were categorized into seven groups based on average daily sleep duration (3-4.9, $5-5 \cdot 9,6-6 \cdot 9,7-7 \cdot 9,8-8 \cdot 9,9-9 \cdot 9$ or $10-12 \mathrm{~h}$ ).

\section{Eating pattern}

Habitual meal frequencies were asked using the following questions: 'During the past year, on average, how many days per week did you eat ... (breakfast, lunch or dinner/supper)?' Snacking frequency was assessed using the following questions: 'During the past year, on average, how many days per week did you have a snack ... (before breakfast, between breakfast and lunch, between lunch and dinner/supper, between supper and bedtime, or after bedtime)?' Snack was defined to exclude foods eaten at meals but to include all beverages except coffee, tea, diet drinks and water. Response categories were $<1$ time/week, 1-2 times/week, 3-4 times/week, 5-6 times/week or 1 time/d for all of the questions; in the analyses they were converted to $0 \cdot 58,1 \cdot 5,3 \cdot 5,5 \cdot 5$ and 7 times/week, respectively.

\section{Dietary data}

The information on dietary intake was obtained from a modified Block FFQ (Block Dietary Data Systems, Berkeley, CA, USA) ${ }^{(19)}$. The questionnaire was structured to collect average food intake during the previous year and a standard portion size was given for each food item. The Healthy Eating Index (HEI) was calculated as the sum of ten dietary components including the degree of conformity to the recommended number of servings for the five major food groups of the Food Guide Pyramid (meat, dairy, fruits, vegetables and grains), proportion of total energy from fat and saturated fat, total cholesterol and sodium intake, and diet variety ${ }^{(20)}$. The glycaemic load was derived from the amount of carbohydrate intake and glycaemic index based on the white bread scale ${ }^{(21)}$.

\section{Statistical analysis}

Characteristics of the study subjects by daily sleep duration are described using the mean and standard deviation for continuous variables and the number and proportion for categorical variables. Principal component analysis was used to identify major eating patterns from weekly frequencies of three meals and five snacks at different times across the day. An individual's score on each of the identified components was computed by summing across the product of the individual's response to each eating frequency item and the corresponding weight (component loading). Nutritional characteristics were compared among four groups categorized on the basis of quartiles of the component scores using ANOVA.

Generalized linear regression models were used to estimate mean component scores for each of the two identified eating patterns by daily sleep duration category. The multivariable models included covariates that are related to either sleep duration or dietary practice as follows: age at enrolment (35-39, 40-44, 45-49, 50-54, 55-59, 60-64, 65-69, 70-74 years); race (non-Hispanic white, black, Hispanic, others); annual household income (<20 000, 20 000-49999, 50 000-99999, 100 000-199999, $\geq 200000$ US dollars); level of education (high school or less, some college or associate/technical degree, college graduate or higher); current employment status (currently working for $\geq 20 \mathrm{~h} /$ week or not); marital status (married/ living as married, widowed/divorced/separated, single); having a child aged 18 years or younger; measured BMI (categorized into three groups using the cut-off points recommended by $\mathrm{WHO}^{(22)}$, where $\mathrm{BMI}<25 \mathrm{~kg} / \mathrm{m}^{2}$ is defined as normal, BMI $>25$ to $<30 \mathrm{~kg} / \mathrm{m}^{2}$ is defined as 
grade 1 overweight and $\mathrm{BMI} \geq 30 \mathrm{~kg} / \mathrm{m}^{2}$ is defined as grade 2 overweight or obese); menopause status; smoking status (never, past, current); use of alcohol in the past 6 months; physical activity in the past 12 months (grouped into quintiles based on the distribution of the sample in MET $\times \mathrm{h} /$ week, where MET is metabolic equivalent) ${ }^{(23)}$; self-rated health status (excellent, very good, good, fair); and perceived level of stress during the past $30 \mathrm{~d}$, measured on the basis of the four-item version of the perceived stress scale developed by Cohen $e t$ al. ${ }^{(24)}$ and categorized into three groups (low, 0-2; medium, 3-7; high, 8-16), based on total score from the four items.

Current obesity $\left(\mathrm{BMI}<30 \mathrm{~kg} / \mathrm{m}^{2} v\right.$. BMI $\left.\geq 30 \mathrm{~kg} / \mathrm{m}^{2}\right)$ and age group $(<55$ years $v$. $\geq 55$ years) were evaluated as potential effect modifiers of the relationship between daily sleep duration and eating patterns using likelihood ratio tests, comparing models with and without multiplicative interaction terms with sleep duration. Analyses were performed using the STATA statistical software package version 10.0 (Stata Corporation, College Station, TX, USA) and all statistical tests were two-sided, with $\alpha$ level of $0 \cdot 05$.

\section{Results}

\section{Characteristics of study subjects by sleep duration}

Approximately $40 \%$ of the women reported sleeping an average of $7-7.9 \mathrm{~h}$ daily, while those with $5-5.9 \mathrm{~h}$ or $<5 \mathrm{~h}$ of sleep daily comprised 5.3\% ( $n$ 1485) and 1.3\% ( $n$ 376), respectively (Table 1 ). Similarly, very few women reported sleeping for $9-9 \cdot 9 \mathrm{~h}$ daily $(3 \cdot 8 \%)$ or $\geq 10 \mathrm{~h}$ daily $(0 \cdot 7 \%)$. Compared with women sleeping $7-7 \cdot 9 \mathrm{~h}$ daily, those with short sleep were more often non-white, current smokers and had a higher BMI. Women who reported sleeping for $\geq 10$ h daily had similar characteristics to those with short sleep, and they also tended to be physically inactive. Total energy intake and macronutrient composition did not substantially vary by daily sleep duration.

\section{Identification and characterization of eating patterns}

Using a principal component analysis, we identified two major components characterizing the overall eating patterns in our study population (Table 2). The two components accounted for $44 \%$ of total variance, had eigenvalues greater than 1 ( 1.9 and $1 \cdot 6$, respectively), and there was a long break between components 2 and 3 on the scree plot (figure not shown), supporting retention of just two components. The two components were also highly interpretable. For the first component, the loading was positively correlated with all three meal frequency items (breakfast, lunch and dinner) and with snacks only between breakfast and dinner times (snack between breakfast and lunch and snack between lunch and dinner); therefore, the first component might be interpreted

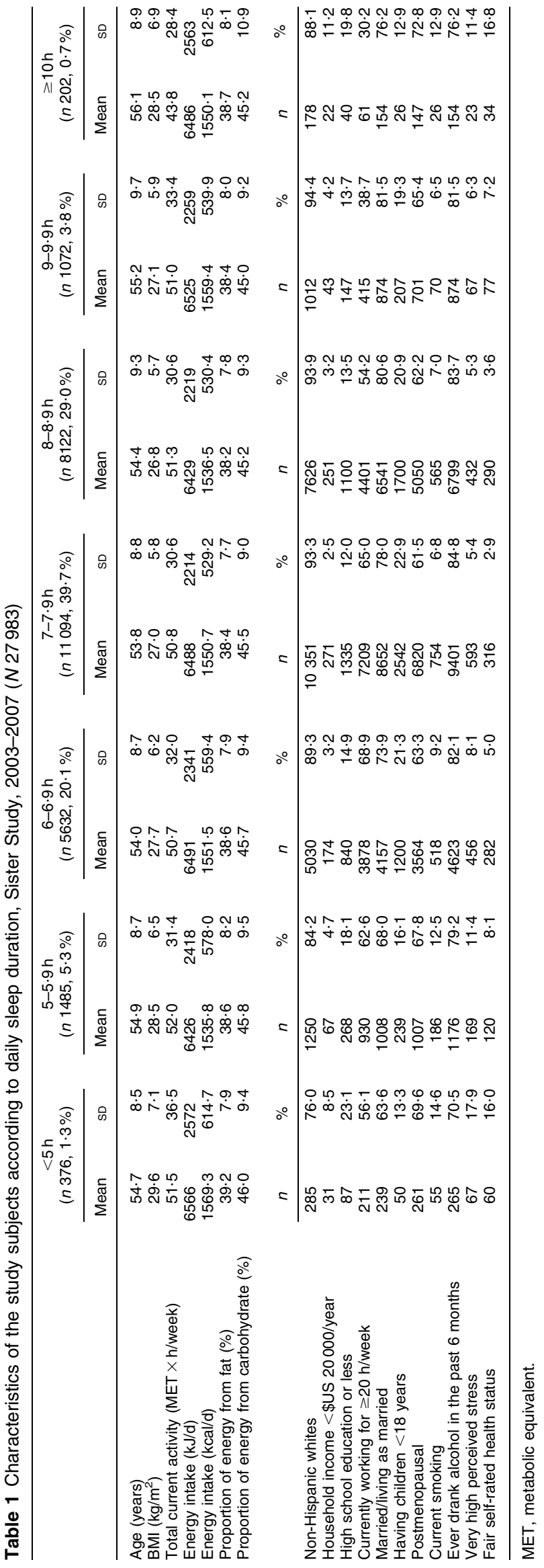


as tendency for eating during conventional eating hours (i.e. from breakfast to dinner). The second component was positively correlated with all five snack frequency items, but inversely correlated with all three meal frequency items. Therefore, the second component may be interpreted as a degree of snack dominance over meals.

Women with increased tendency for eating during conventional eating hours had higher total energy intake and glycaemic load, but they consumed proportionally less fat and sweets and had higher HEI scores (Table 3). On the other hand, increasing snack dominance over meals was related to lower HEI scores and greater intakes of sweets and fat for energy (Table 4).

\section{Association between sleep duration and eating patterns}

The tendency for eating during conventional hours (from breakfast to dinner) increased with increasing sleep duration up to $7-7 \cdot 9 \mathrm{~h}$ : adjusted mean score of $-0.54(95 \%$ CI $-0 \cdot 68,-0 \cdot 41)$ in women sleeping $<5$ h daily $v$. 0.08 (95\% CI $0 \cdot 06,0 \cdot 11)$ among those with $7-7 \cdot 9$ h of sleep daily (Fig. 1). The extent of snack dominance over meals

Table 2 Component loading for eating patterns from principal component analysis, Sister Study, 2003-2007 (N 27983)

\begin{tabular}{|c|c|c|c|c|}
\hline & \multicolumn{2}{|c|}{ Frequency (times/week) } & \multirow{2}{*}{$\begin{array}{l}\text { Component 1: Eating episodes } \\
\text { during conventional eating hours }\end{array}$} & \multirow{2}{*}{$\begin{array}{l}\text { Component 2: Dominance } \\
\text { of snacks over meals }\end{array}$} \\
\hline & Mean & $\mathrm{SD}$ & & \\
\hline Breakfast & $5 \cdot 6$ & $2 \cdot 0$ & 0.49 & $-0 \cdot 13$ \\
\hline Lunch & $6 \cdot 0$ & $1 \cdot 1$ & 0.54 & $-0 \cdot 16$ \\
\hline Dinner & $6 \cdot 4$ & $1 \cdot 1$ & 0.47 & -0.19 \\
\hline Snack before breakfast & $0 \cdot 8$ & $1 \cdot 0$ & -0.08 & $0 \cdot 46$ \\
\hline Snack between breakfast and lunch & $2 \cdot 2$ & $2 \cdot 1$ & 0.28 & 0.46 \\
\hline Snack between lunch and dinner & $3 \cdot 5$ & $2 \cdot 2$ & $0 \cdot 36$ & 0.41 \\
\hline Snack after dinner & $3 \cdot 0$ & $2 \cdot 3$ & $0 \cdot 14$ & 0.37 \\
\hline Snack after bedtime & $0 \cdot 8$ & 0.9 & $-0 \cdot 12$ & 0.44 \\
\hline Variance explained (\%) & & & $23 \cdot 80$ & $20 \cdot 20$ \\
\hline
\end{tabular}

Table 3 Nutritional characteristics according to quartile of conventional eating score*, Sister Study, 2003-2007 (N 27983 )

\begin{tabular}{|c|c|c|c|c|c|c|c|c|}
\hline & \multicolumn{2}{|c|}{$\begin{array}{c}\text { Q1 } \\
(<-0 \cdot 89)\end{array}$} & \multicolumn{2}{|c|}{$\begin{array}{c}\text { Q2 } \\
(-0.89-<0.24)\end{array}$} & \multicolumn{2}{|c|}{$\begin{array}{c}\text { Q3 } \\
(0 \cdot 24-<1 \cdot 01)\end{array}$} & \multicolumn{2}{|c|}{$\begin{array}{c}\text { Q4 } \\
(1 \cdot 01-<2 \cdot 50)\end{array}$} \\
\hline & Mean & SD & Mean & SD & Mean & SD & Mean & SD \\
\hline Energy intake (kJ/d) & 5940 & 2320 & 6380 & 2239 & 6535 & 2130 & 7029 & 2220 \\
\hline Energy intake (kcal/d) & $1419 \cdot 6$ & $554 \cdot 5$ & $1524 \cdot 9$ & $535 \cdot 1$ & $1561 \cdot 9$ & $509 \cdot 2$ & $1679 \cdot 9$ & $530 \cdot 7$ \\
\hline Proportion of energy from fat (\%) & 38.9 & $8 \cdot 0$ & $38 \cdot 6$ & $7 \cdot 7$ & $38 \cdot 0$ & $7 \cdot 7$ & $38 \cdot 1$ & $7 \cdot 7$ \\
\hline Proportion of energy from protein (\%) & $15 \cdot 9$ & $3 \cdot 3$ & $15 \cdot 7$ & $3 \cdot 1$ & $16 \cdot 0$ & $3 \cdot 0$ & $16 \cdot 0$ & $2 \cdot 9$ \\
\hline Proportion of energy from carbohydrate (\%) & $44 \cdot 8$ & $9 \cdot 9$ & $45 \cdot 0$ & $9 \cdot 1$ & $45 \cdot 7$ & $9 \cdot 0$ & $46 \cdot 3$ & $8 \cdot 8$ \\
\hline Proportion of energy from sweets (\%) & $14 \cdot 8$ & $10 \cdot 7$ & $13 \cdot 2$ & $9 \cdot 1$ & $11 \cdot 9$ & $8 \cdot 0$ & $12 \cdot 7$ & $8 \cdot 4$ \\
\hline Daily number of fruit/vegetable servings & $3 \cdot 8$ & $2 \cdot 5$ & $4 \cdot \overline{7}$ & $2 \cdot 7$ & $5 \cdot 2$ & $2 \cdot 7$ & $5 \cdot 6$ & $2 \cdot 9$ \\
\hline Healthy Eating Index & $57 \cdot 0$ & $12 \cdot 2$ & $62 \cdot 0$ & $12 \cdot 5$ & $65 \cdot 5$ & $12 \cdot 6$ & $67 \cdot 0$ & $12 \cdot 1$ \\
\hline Daily glycaemic load based on white bread scale & $107 \cdot 6$ & $51 \cdot 8$ & $114 \cdot 2$ & $48 \cdot 0$ & $117 \cdot 5$ & $46 \cdot 0$ & $127 \cdot 4$ & $48 \cdot 9$ \\
\hline
\end{tabular}

${ }^{*}$ All nutritional characteristics compared were significantly different among the four groups $(P<0.01)$.

Table 4 Nutritional characteristics according to quartile of snack dominance score* ${ }^{\star}$ Sister Study, 2003-2007 (N 27 983)

\begin{tabular}{|c|c|c|c|c|c|c|c|c|}
\hline & \multicolumn{2}{|c|}{$\begin{array}{c}\text { Q1 } \\
(<-0 \cdot 81)\end{array}$} & \multicolumn{2}{|c|}{$\begin{array}{c}\mathrm{Q} 2 \\
(-0 \cdot 81-<-0 \cdot 22)\end{array}$} & \multicolumn{2}{|c|}{$\begin{array}{c}\text { Q3 } \\
(-0.22-<0.55)\end{array}$} & \multicolumn{2}{|c|}{$\begin{array}{c}\mathrm{Q} 4 \\
0.55-<9.40)\end{array}$} \\
\hline & Mean & SD & Mean & SD & Mean & SD & Mean & SD \\
\hline Energy intake (kJ/d) & 5978 & 1996 & 6263 & 2143 & 6651 & 2297 & 6979 & 2454 \\
\hline Energy intake $(\mathrm{kcal} / \mathrm{d})$ & $1428 \cdot 7$ & $477 \cdot 1$ & $1497 \cdot 0$ & $512 \cdot 3$ & $1589 \cdot 6$ & $549 \cdot 0$ & $1668 \cdot 1$ & $586 \cdot 6$ \\
\hline Proportion of energy from fat (\%) & $37 \cdot 6$ & $8 \cdot 1$ & $38 \cdot 3$ & $7 \cdot 6$ & $38 \cdot 8$ & $7 \cdot 7$ & 38.9 & $7 \cdot 8$ \\
\hline Proportion of energy from protein (\%) & $16 \cdot 0$ & $3 \cdot 1$ & $15 \cdot 9$ & $3 \cdot 1$ & $15 \cdot 6$ & $3 \cdot 1$ & $15 \cdot 3$ & $3 \cdot 2$ \\
\hline Proportion of energy from carbohydrate (\%) & $45 \cdot 1$ & $9 \cdot 7$ & $45 \cdot 1$ & $9 \cdot 1$ & $45 \cdot 4$ & $8 \cdot 9$ & $46 \cdot 3$ & $9 \cdot \overline{1}$ \\
\hline Proportion of energy from sweets (\%) & $10 \cdot 5$ & $7 \cdot 7$ & $12 \cdot 3$ & $8 \cdot 3$ & $14 \cdot 1$ & $9 \cdot 0$ & $15 \cdot 7$ & $10 \cdot 6$ \\
\hline Daily number of fruit/vegetable servings & 4.9 & $2 \cdot 7$ & $4 \cdot 8$ & $2 \cdot 7$ & $4 \cdot 7$ & $2 \cdot 7$ & $4 \cdot 8$ & $2 \cdot 9$ \\
\hline Healthy Eating Index & $64 \cdot 2$ & $12 \cdot 9$ & $63 \cdot 0$ & $12 \cdot 8$ & $62 \cdot 4$ & $12 \cdot 9$ & $61 \cdot 8$ & $12 \cdot 9$ \\
\hline Daily glycaemic load based on white bread scale & $105 \cdot 4$ & $43 \cdot 1$ & $111 \cdot 6$ & $46 \cdot 5$ & $120 \cdot 6$ & $49 \cdot 8$ & $128 \cdot 9$ & $53 \cdot 6$ \\
\hline
\end{tabular}

*All nutritional characteristics compared were significantly different among the four groups $(P<0 \cdot 01)$ except for daily number of fruit/vegetable servings $(P=0.06)$. 


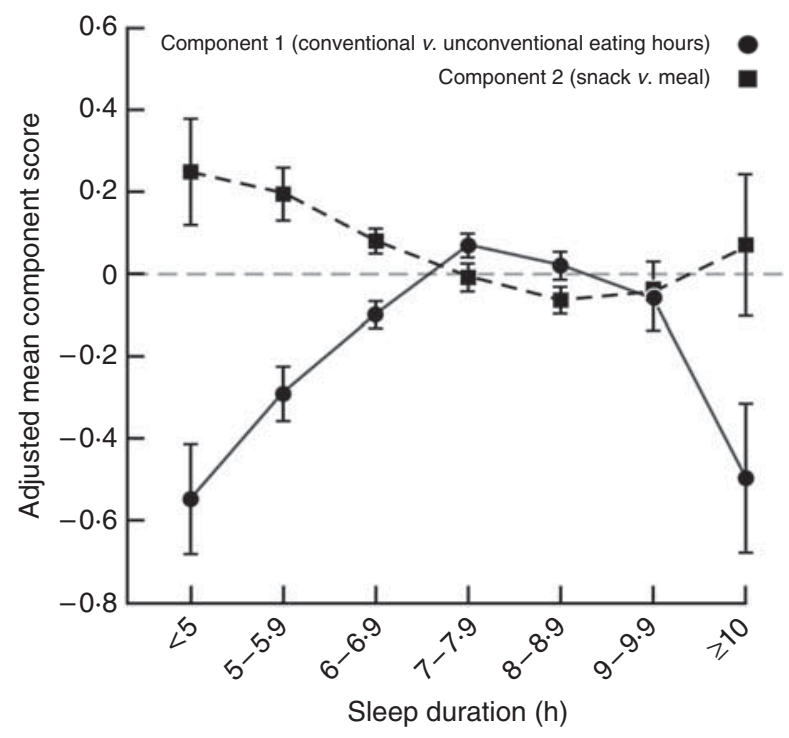

Fig. 1 Adjusted mean component scores for eating patterns by sleep duration among 27983 women aged 35-74 years in the Sister Study, 2003-2007. Each circle represents adjusted mean score for eating during conventional eating hours and each square represents adjusted mean score for snacking by daily sleep duration category, estimated from multivariable models including age, race, household income, education, marital status, having children $<18$ years old, smoking status, current alcohol use, menopausal status, self-rated health, perceived level of stress, physical activity and measured BMI. $95 \%$ confidence intervals represented by vertical bars

decreased with increasing sleep duration, with mean score of $0.24(95 \%$ CI $0 \cdot 11,0 \cdot 38)$ in those with $<5$ h of sleep daily $v$. $-0.07(95 \% \mathrm{CI}-0 \cdot 10,-0 \cdot 04)$ in women sleeping for $8-8.9 \mathrm{~h}$ daily. Women with long daily sleep duration $(\geq 10 \mathrm{~h}$ ) had scores for both eating patterns similar to those with less than normal sleep duration $(<6 \mathrm{~h})$.

The relationship between daily sleep duration and eating patterns did not vary by obesity. Instead, we observed that obesity was associated with a lower tendency for eating during conventional eating hours and a greater degree of snack dominance over meals regardless of sleep duration (Fig. 2a). We also found a significant interaction between sleep duration and age for the degree of snack dominance over meals (likelihood ratio test $P=0 \cdot 02$; Fig. $2 \mathrm{~b}$ ).

\section{Discussion}

In this analysis of 27983 women, we identified distinctive eating patterns that were associated with sleep duration. Compared with women with normative sleep duration (7-7.9h daily), short sleep duration and, to a lesser extent, long sleep duration were both associated with reduced tendency for eating during conventional eating hours and greater degree of snack dominance over meals.

Eating during unconventional hours (i.e. before breakfast and after bedtime) may reflect accommodations made to adjust to short sleep duration. In our exploratory analysis, short sleepers tended to go to bed later than those with normative sleep duration, thereby having more opportunities for eating at later hours. Furthermore, staying awake at night alone may also lead to physiological changes that promote hunger. In an experimentally controlled study, those who stayed awake later at night had lower concentrations of the anorexigenic hormone leptin without a notable peak at night compared with subjects who were asleep by 22.30 hours ${ }^{(16)}$. Likewise, women with short sleep duration also tend to get up early and are more likely to replace breakfast with an early morning snack, supported by the previous findings of a higher prevalence of skipping breakfast in persons with short sleep duration $^{(16)}$. Given that the preceding meal largely determines the size and the time of the following meal ${ }^{(25)}$, substitution of breakfast with an early morning snack could subsequently affect eating patterns throughout the day. Thus, greater snack dominance over meals observed in habitual short sleepers may represent deviations in eating patterns arising from early rising or late bedtime.

The present study also showed that the eating patterns prevalent among short and long sleepers were reflective of a nutritionally poor diet; both eating during unconventional eating hours and preponderance of snacks over meals were related to lower intakes of fruits and vegetables and higher intakes of sweets and fat as a percentage of energy.

Snacks are generally composed of foods with higher carbohydrate and lower protein, and frequent snacking was found to be a good predictor of nutritionally empty and energy-laden diet in a previous study ${ }^{(13)}$. On the other hand, breakfast often consists of foods with low fat and high carbohydrate and fibre contents ${ }^{(26,27)}$, and skipping breakfast is considered to lead to intake of compensatory snacks with relatively poor nutritional quality or overeating in later meals ${ }^{(27)}$. Compared with individuals who regularly eat breakfast, those who skip breakfast had a lower micronutrient intake, a higher energy intake from fat and a higher level of LDL cholesterol ${ }^{(27,28)}$.

Night-time eating also has been positively correlated with fat, carbohydrate and total energy intakes ${ }^{(29)}$, and has been more commonly reported in obese women than among non-obese women ${ }^{(30)}$. Moreover, food intake at a later time of day may induce different physiological responses to food: it has been suggested that food intake in the evening or night is more likely than food consumed at other times of the day to preserve glycogen levels in muscles, ultimately leading to higher adiposity ${ }^{(31)}$.

Some limitations of the present study should be acknowledged. First, our participants were volunteers. As in other volunteer populations, compared with the general US population, they were more educated and had higher incomes on average, which might limit the external generalizability of our results. However, the associations between sociodemographic factors and sleep duration 
Component 1 (conventional $v$. unconventional eating hours)
Component 2

(snack v. meal)

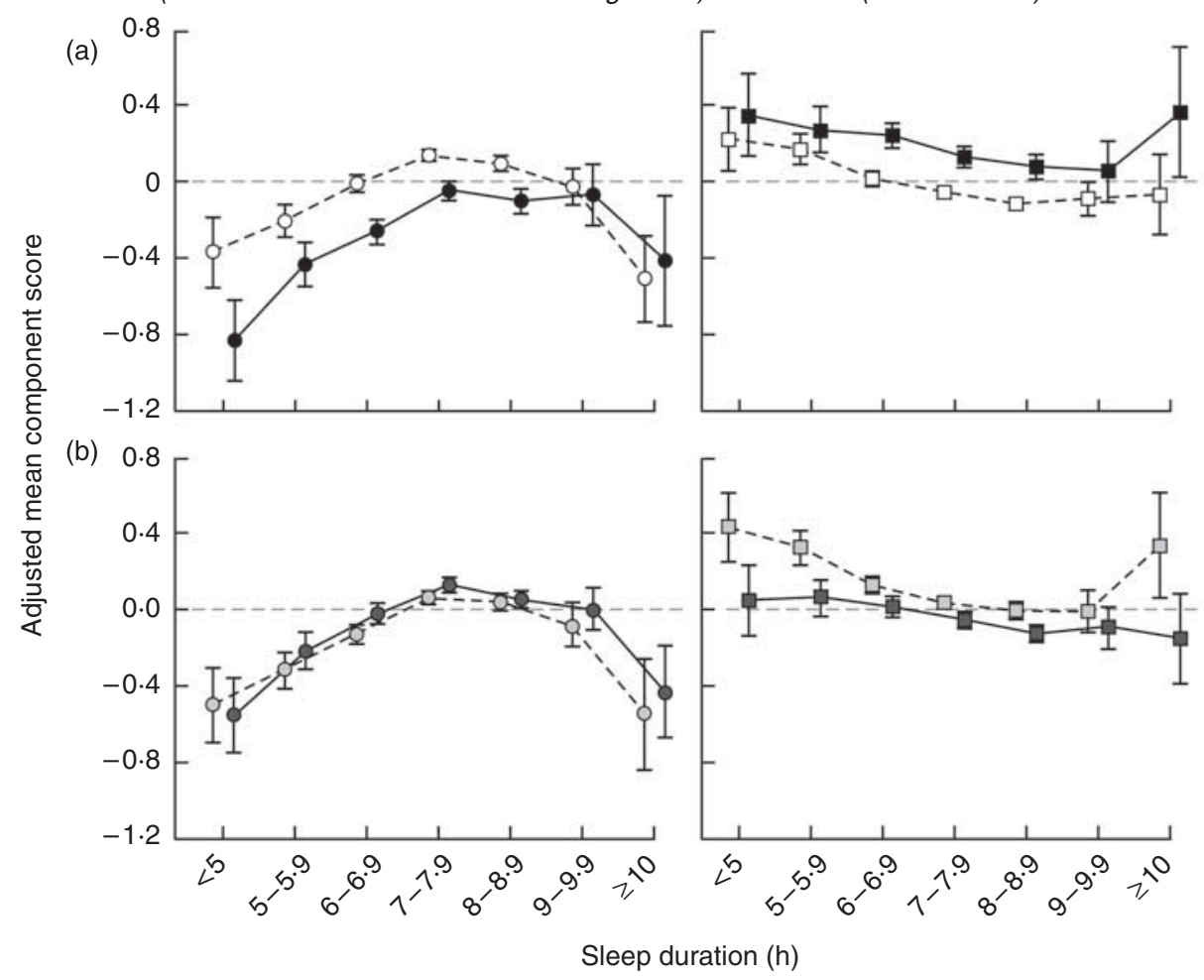

Fig. 2 Adjusted mean component scores for eating patterns by sleep duration, according to obesity $\left(\bigcirc, \square, \mathrm{BMI}<30 \mathrm{~kg} / \mathrm{m}^{2}\right.$; $\left.\mathrm{BMI} \geq 30 \mathrm{~kg} / \mathrm{m}^{2}\right)$ and age $(\mathrm{O}, \mathrm{O},<55$ years; $\square, \square, \geq 55$ years) among 27983 women aged $35-74$ years in the Sister Study, 2003-2007. Each circle represents adjusted mean score for eating during conventional eating hours and each square represents adjusted mean score for snacking by daily sleep duration category, estimated from multivariable generalized linear models including age, race, household income, education, marital status, having children $<18$ years old, smoking status, current alcohol use, menopausal status, self-rated health, perceived level of stress, physical activity and measured BMI. $95 \%$ confidence intervals represented by vertical bars. (a) The relationship between sleep duration and eating patterns did not vary by obesity $(P=0 \cdot 13$ for component 1 and $P=0.65$ for component 2, likelihood ratio test); (b) the association between sleep duration and eating during conventional hours did not vary by age $(P=0 \cdot 53$, likelihood ratio test), but the association between sleep duration and snack dominance eating pattern was stronger in women aged $<55$ years than among women aged $\geq 55$ years $(P=0.02$, likelihood ratio test)

observed in our study were similar to those from the National Health Interview Survey ${ }^{(32)}$, suggesting that, at least in terms of sleep duration, our participants are comparable to a nationally representative US sample.

Second, there have been no established approaches to define what constitutes a 'meal' $v$. a 'snack' ${ }^{(33)}$. In the present study, 'snack' was loosely defined as an eating episode between meals except for non-caloric drinks and no clear definition of 'meal' was provided; thus, number, size and timing of 'meals' may be subject to individual variations in sociocultural norms and chronological trends ${ }^{(33)}$. However, we were unable to evaluate the impact of such misclassification on the present findings.

Finally, although it was assumed that sleep duration was a prior event influencing eating patterns, we recognize that the relationship between sleep duration and eating patterns is likely to be bidirectional. Data suggest that sleep loss alters physiological regulation of metabolic hormones, which not only influences diet and eating patterns but also feeds back to affect the sleep-wake regulatory process itself $f^{(9)}$. Conversely, it is also possible that short sleep duration and the associated eating patterns may be a manifestation of either genetically or non-genetically altered circadian rhythms ${ }^{(9)}$. Mice with mutations in the clock gene that disrupt cellular rhythmicity showed a significant increase in energy intake and body weight, and higher levels of leptin and glucose, compared with wild-type mice ${ }^{(15)}$. In man, polymorphisms in the clock gene have been associated with sleep deregulation $^{(34)}$.

In conclusion, our data show that short and very long sleep duration are associated with eating during unconventional eating hours and snacking. Combined with growing evidence indicating circadian variation in physiological responses to foods ${ }^{(31)}$, these results suggest that disrupted eating patterns may exacerbate the development of obesity and metabolic diseases in habitual short and very long sleepers via poor nutritional composition and altered physiological responses to nutrients. 


\section{Acknowledgements}

Sources of funding: This research was funded by the Intramural Research Program of the NIH, NIEHS (Z01 ES04400509) with additional support from the National Center on Minority Health and Health Disparities. Conflict of interest: No actual or potential conflict of interest is declared. Authors' contributions: S.K. conceptualized the study and analysed the data. S.K. drafted the manuscript; S.K., L.A.D. and D.P.S. contributed to the interpretation of the data, discussion of the findings and revision of the manuscript. D.P.S. obtained the funding. Acknowledgements: The authors thank Drs Honglei Chen and Matthew Longnecker for helpful comments on this manuscript.

\section{References}

1. Gangwisch JE, Malaspina D, Boden-Albala B et al. (2005) Inadequate sleep as a risk factor for obesity: analyses of the NHANES I. Sleep 28, 1289-1296.

2. Hasler G, Buysse DJ, Klaghofer R et al. (2004) The association between short sleep duration and obesity in young adults: a 13-year prospective study. Sleep 27, 661-666.

3. Vorona RD, Winn MP, Babineau TW et al. (2005) Overweight and obese patients in a primary care population report less sleep than patients with a normal body mass index. Arch Intern Med 165, 25-30.

4. Courno M, Ruidavets JB, Marquie JC et al. (2004) Environmental factors associated with body mass index in a population of southern France. Eur J Cardiovasc Prev Rehabil 11, 291-297.

5. Ayas NT, White DP, Al-Delaimy WK et al. (2003) A prospective study of self-reported sleep duration and incident diabetes in women. Diabetes Care 26, 380-384.

6. Knutson KL, Ryden AM, Mander BA et al. (2006) Role of sleep duration and quality in the risk and severity of type 2 diabetes mellitus. Arch Intern Med 166, 1768-1774.

7. Tasali E, Leproult R, Ehrmann DA et al. (2008) Slow-wave sleep and the risk of type 2 diabetes in humans. Proc Natl Acad Sci USA 105, 1044-1049.

8. Patel SR \& Hu FB (2008) Short sleep duration and weight gain: a systematic review. Obesity (Silver Spring) 16, 643-653.

9. Laposky AD, Bass J, Kohsaka A et al. (2008) Sleep and circadian rhythms: key components in the regulation of energy metabolism. FEBS Lett 582, 142-151.

10. Bellisle F, McDevitt R \& Prentice AM (1997) Meal frequency and energy balance. Br J Nutr 77, Suppl. 1, S57-S70.

11. Nicklas TA, Baranowski T, Cullen KW et al. (2001) Eating patterns, dietary quality and obesity. J Am Coll Nutr 20, 599-608.

12. Ma Y, Bertone ER, Stanek EJ III et al. (2003) Association between eating patterns and obesity in a free-living US adult population. Am J Epidemiol 158, 85-92.

13. Berteus FH, Lindroos AK, Sjostrom L et al. (2002) Meal patterns and obesity in Swedish women - a simple instrument describing usual meal types, frequency and temporal distribution. Eur J Clin Nutr 56, 740-747.

14. Shigeta H, Shigeta M, Nakazawa A et al. (2001) Lifestyle, obesity, and insulin resistance. Diabetes Care 24, 608.
15. Turek FW, Joshu C, Kohsaka A et al. (2005) Obesity and metabolic syndrome in circadian Clock mutant mice. Science 308, 1043-1045.

16. Qin LQ, Li J, Wang Y et al. (2003) The effects of nocturnal life on endocrine circadian patterns in healthy adults. Life Sci 73, 2467-2475.

17. Quandt SA, Vitolins MZ, DeWalt KM et al. (1997) Meal patterns of older adults in rural communities: life course analysis and implications for undernutrition. $J$ Appl Gerontol 16, 152-171.

18. Slesinger DP, McDivitt M \& O'Donnell FM (1980) Food patterns in an urban population: age and sociodemographic correlates. J Gerontol 35, 432-441.

19. Block G, Hartman AM, Dresser CM et al. (1986) A databased approach to diet questionnaire design and testing. Am J Epidemiol 124, 453-469.

20. Kennedy ET, Ohls J, Carlson S et al. (1995) The Healthy Eating Index: design and applications. J Am Diet Assoc 95, 1103-1108.

21. Wolever TM, Nuttall FQ, Lee R et al. (1985) Prediction of the relative blood glucose response of mixed meals using the white bread glycemic index. Diabetes Care 8, 418-428.

22. World Health Organization (1997) Obesity: Preventing and Managing the Global Epidemic. WHO Consultation on Obesity. WHO Technical Report Series no. 894. Geneva: WHO.

23. Ainsworth BE, Haskell WL, Leon AS et al. (1993) Compendium of physical activities: classification of energy costs of human physical activities. Med Sci Sports Exerc 25, 71-80.

24. Cohen S, Kamarck T \& Mermelstein R (1983) A global measure of perceived stress. J Health Soc Behav 24, 385-396.

25. Bernstein IL, Zimmerman JC, Czeisler CA et al. (1981) Meal patterns in 'free-running' humans. Physiol Behav 27, 621-623.

26. Morgan KJ, Zabik ME \& Stampley GL (1986) The role of breakfast in diet adequacy of the US adult population. $J \mathrm{Am}$ Coll Nutr 5, 551-563.

27. Ruxton CH \& Kirk TR (1997) Breakfast: a review of associations with measures of dietary intake, physiology and biochemistry. Br J Nutr 78, 199-213.

28. Wyatt HR, Grunwald GK, Mosca CL et al. (2002) Long-term weight loss and breakfast in subjects in the National Weight Control Registry. Obes Res 10, 78-82.

29. de Castro JM (2007) The time of day and the proportions of macronutrients eaten are related to total daily food intake. Br J Nutr 98, 1077-1083.

30. O'Reardon JP, Ringel BL, Dinges DF et al. (2004) Circadian eating and sleeping patterns in the night eating syndrome. Obes Res 12, 1789-1796.

31. Keim NL, Van Loan MD, Horn WF et al. (1997) Weight loss is greater with consumption of large morning meals and fat-free mass is preserved with large evening meals in women on a controlled weight reduction regimen. $J$ Nutr 127, 75-82.

32. Adams PF \& Schoenborn CA (2006) Health behaviors of adults: United States, 2002-04. Vital Health Stat 10, issue $230,1-140$

33. Gatenby SJ (1997) Eating frequency: methodological and dietary aspects. Br J Nutr 77, Suppl, 1, S7-S20.

34. Prasai MJ, George JT \& Scott EM (2008) Molecular clocks, type 2 diabetes and cardiovascular disease. Diab Vasc Dis Res 5, 89-95. 